\title{
昡pubvet
}

https://doi.org/10.31533/pubvet.v15n05a824.1-8

\section{Uso de pele de tilápia em disjunção de sínfise mandibular em felino: Relato de caso}

\author{
Francielli Lara Machado ${ }^{\circ}$, Danielle Cristine Borges da Silva ${ }^{2}{ }^{\circ}$, Carla dos Santos Taveira ${ }^{30}$, \\ Francielle Aparecida Sousa ${ }^{4 * 0}$ \\ ${ }^{I}$ Graduanda do curso de Medicina Veterinária. Centro Universitário do Cerrado Patrocínio - UNICERP. \\ ${ }^{2}$ Médica Veterinária. Universidade de Uberaba - UNIUBE. \\ ${ }^{3}$ Médica Veterinária. Universidade Federal de Minas Gerais - UFMG. \\ ${ }^{4}$ Mestre em Produção e Sanidade Animal, docente e coordenadora do curso de Medicina Veterináriado Centro Universitánio do Cerrado Patrocínio-UNICERP Patrocínio/MG. \\ *Autor para correspondência, E-mail: francisousavet@gmail.com
}

Resumo. Os traumas mandibulares são comuns em pequenos animas e a região mais acometida em gatos é a sínfise mentoniana. Com o impacto traumático o animal apresenta um quadro de lesões com descontinuidade de tecidos anatômicos e celular, levando a fraturas expostas e não expostas. Como opções terapêuticas há métodos cirúrgicos como pino intramedular, fixação esquelética externa, cerclagem e o uso de acrílicos e placas ósseas. Para a região lesionada o indicado é o uso de curativos baratos e flexíveis proporcionando conforto e bem-estar ao paciente, para que no final alcance a consolidação da sínfise e restabeleça funcionalidade oral ao animal. Logo, surge como alternativa de material biológico, o uso da pele de tilápia do Nilo, fornecendo todas as características que o animal necessita para reepitelização, conforto, flexibilidade, excelente aderência e redução de perdas hidroeletrolíticas. Portanto esse trabalho visa relatar o uso da pele de tilápia do Nilo associado à pomada Dersani ${ }^{\circledR}$ como curativo oclusivo temporário em disjunção de sínfise mandibular após necrose epitelial, em um felino, SRD de aproximadamente 4 meses de idade. A pele foi previamente preparada no Centro Universitário do Cerrado (UNICERP), em laboratório estéril. Para isso utilizou-se solução de clorexidina dergemante a $2 \%$ e solução fisiológica $0,9 \%$. Repetiu-se a técnica por 3 vezes, sempre removendo todo material da couraça que não seria utilizado, preservando as escamas e o couro do produto. Após a higienização, o material foi embalado, identificado e armazenado na geladeira para refrigeração, utilizando como meio de armazenamento $80 \%$ de solução fisiológica e $20 \%$ de glicerina. Em seguida, foi mensurado o tamanho das bordas com o uso de um paquímetro e posteriormente foi higienizado o local da lesão e escarificado para colocação do material biológico. A pele de tilápia foi trocada a cada 3-4 dias, sempre verificando a evolução da ferida e a presença de infecções e inflamações, durante aproximadamente 17 dias. Em suma, observamos a evolução da ferida que permanecia sempre limpa e livre de infecções, deixando o animal calmo e com bem-estar. A técnica demonstrou ser efetiva, trazendo agilidade no pós-operatório e monetariamente mais viável ao proprietário.

Palavras-chave: Oreochromis niloticus, pós-operatório, queimadura, sínfise mentoniana, trauma

\section{Use of tilapia skin in mandibular symphysis disjunction in feline: Case report}

Abstract: Mandibular trauma is common in small animals and the region most affected in cats is the mental symphysis. With the traumatic impact, the animal presents a picture of injuries with discontinuity of anatomical and cellular tissues, leading to open and 
unexposed fractures. As therapeutic options, there are surgical methods such as intramedullary pin, external skeletal fixation, cerclage and the use of acrylics and bone plates. For the injured region, the use of cheap and flexible dressings is recommended, providing comfort and well-being to the patient, so that in the end it reaches the consolidation of the symphysis and restores oral functionality to the animal. Therefore, the use of Nile tilapia skin appears as an alternative to biological material, providing all the characteristics that the animal needs for re-epithelialization, comfort, flexibility, excellent adhesion and reduction of hydroelectrolytic losses. Therefore, this work aims to report the use of Nile tilapia skin associated with Dersani ${ }^{\circledR}$ ointment as a temporary occlusive dressing in mandibular symphysis disjunction after epithelial necrosis, in a feline, SRD of approximately 4 months of age. The skin was previously prepared at the Centro Universitário do Cerrado (UNICERP), in a sterile laboratory. For this, a $2 \%$ chlorhexidine solution was used and a $0.9 \%$ saline solution. The technique was repeated 3 times, always removing all material from the harness that would not be used, preserving the scales and leather of the product. After cleaning, the material was packaged, identified and stored in the refrigerator for refrigeration, using $80 \%$ saline solution and $20 \%$ glycerin as storage medium. Then, the size of the edges was measured with the use of a caliper and subsequently the area of the lesion was cleaned and scarified for placement of the biological material. The tilapia skin was changed every 3-4 days, always checking the evolution of the wound and the presence of infections and inflammations, for approximately 17 days. In short, we observed the evolution of the wound that always remained clean and free of infections, leaving the animal calm and well-being. The technique proved to be effective, bringing agility in the postoperative and monetarily more viable to the owner.

Keywords: Oreochromis niloticus, postoperative, burn, mental symphysis, trauma

\section{Introdução}

Os ossos da mandíbula e maxila abrangem a maior porção facial dos felinos, são responsáveis pela mastigação, fonação, deglutição e manutenção da normoclusão dentária. Os traumas mandibulares são comuns em pequenos animas e a região mais acometida em gatos é a sínfise mentoniana. Grandes inserções musculares facilitam a mobilidade mandibular, o que auxilia anatomicamente sua fragmentação em locais diferentes. As fraturas são classificadas em exposta e não expostas podendo ser favoráveis, com ausência de deslocamento dos fragmentos ósseos e desfavoráveis, com a presença do deslocamento de fragmentos ósseos (Dias et al., 2012).

Com o impacto traumático, o animal apresenta um quadro de lesões com descontinuidade de tecidos anatômicos e celular, sendo classificadas em abertas e fechadas, variando conforme sua apresentação (Borella et al., 2019). Em alguns casos, concomitante a ferida, ocorre queimaduras devido a força traumática ou calor exercido no local, no qual, desenvolvem queimaduras de primeiro até terceiro grau, capazes de desencadear respostas inflamatórias sistémicas ou a morte tecidual por necrose (Lima-Junior et al., 2017; Torrisi et al., 2018).

Para um tratamento completo, o profissional possui opções terapêuticas que vão desde métodos mais conservadores até opções cirúrgicas para que no final alcance a consolidação da sínfise e restabeleça funcionalidade oral ao animal (Dias et al., 2012). Os métodos mais utilizados cirurgicamente para fixação das fraturas em sínfise são a utilização de pinos intramedulares, fixadores externos, placas, fios metálicos e incorporação de acrílico (Nelson \& Couto, 2015). Na lesão o ideal é o uso de curativos baratos e de fácil obtenção com excelente flexibilidade e aderência, resistência à distensão, fácil manipulação, que reduza o processo inflamatório e forneça analgesia (E. M. L. Lima-Júnior, 2017; Nelson \& Couto, 2015).

Outro método que pode ser utilizado nessas feridas e/ou traumas são materiais biológicos ou sintéticos, na tentativa de ocluir a lesão. Esses produtos visam reduzir perdas hidroeletrolíticas, contaminações bacterianas até que o tecido esteja viável para sua reepitelização, evitando assim as frequências das trocas dos curativos. As trocas dos curativos devem ser realizadas em intervalos regulares que variam conforme o tipo de material utilizado onde devem ser observados formações de aderências ou infecções. Mas devido ao elevado custo e menos eficazes em lesões profundas, os curativos oclusivos sintéticos ou biossintéticos não tem demostrado ser opções viáveis para o tratamento 
em pequenos animais. Portanto, existe uma busca por materiais biológicos como alternativa para o tratamento de lesões primárias em traumas e queimaduras (Lima-Junior et al., 2017).

O uso da pele de tilápia do Nilo (Oreochromis niloticus) surge como uma alternativa de material biológico utilizáveis pela bioengenharia, principalmente por aderir consistentemente na área lesionada. Originário da bacia do rio Nilo, no leste da África, pertencente à família dos ciclídeos e é encontrado amplamente nas regiões tropicais e subtropicais (Lima-Junior et al., 2017; Miranda, 2018; Torrisi et al., 2018). Foi introduzida no país em 1971, através do Departamento Nacional de Obras Contra a Seca (DNOCS) nos açudes nordestinos, ocupando hoje, todo o território nacional (Lima-Júnior et al., 2019; Lima Júnior, 2017).

Subproduto destinado à produção de couro onde a maioria é descartada, é um material nobre e com alta qualidade de resistência. Pesquisadores da Universidade Federal do Ceará, desenvolveram aspectos histomorfológicos de tipificação do colágeno tipo I e características físicas de resistência à tração (LimaJunior et al., 2017; Miranda, 2018; Torrisi et al., 2018). Tornando, portanto, uma opção viável para a utilização em feridas e queimaduras de pequenos animais. Associado à ele pode-se fazer o uso da pomada hidrogel Dersani ${ }^{\circledR}$, que possui em sua composição o ácido cáprico, ácido caprílico, ácido capróico, ácido láurico, ácido linoleico, lectina, palmitato de retinol, acetato de tocoferol e alfatocoferol. Esse fármaco auxilia no processo de cicatrização e lubrificação das lesões (Sousa, 2018).

Portanto esse trabalho visa relatar o uso da pele de tilápia do Nilo associado a pomada Dersani ${ }^{\circledR}$, como curativo oclusivo temporário em disjunção de sínfise mandibular em felinos, após necrose epitelial. Visando acompanhar a evolução da lesão, reduzindo o custo do procedimento, contaminação e inflamações, bem como, proporcionar qualidade e bem-estar ao paciente durante todo o pós-operatório.

\section{Relato de caso}

A paciente deu entrada na Clínica Veterinária Cães e Cia, localizada no município de Patrocínio/ MG, no dia vinte e cinco de fevereiro de dois mil e vinte, uma gata SRD com trauma na sínfise mandibular na região mentoniana. $\mathrm{O}$ animal pesava $1,80 \mathrm{~kg}$ sendo que a responsável pela paciente havia a encontrado na rua, adotando a mesmo posteriormente, sendo chamada de Sofia. Por ser um animal errante, estima-se que a idade aparente era em torno de 4 meses. Foi realizado o atendimento emergencial pela médica veterinária Danielle Borges, com a realização de hemograma completo e exames complementares de raio-x e Fiv/Felv. Após a análise do exame de sangue, constatou-se uma anemia com eritropenia discreta, sendo uma anemia não responsiva (baixo reticulócitos), baixo hematócrito, baixa de hemoglobina e eosinopenia, como indicado no Anexo 1.

Ao realizar o teste rápido para FIV/FeLV constatou-se que o animal não apresentava nenhuma dessas patologias, conforme Tabela 1, sendo recomendado posteriormente o tratamento para anemia com suplementação e fármacos, No exame de raio-x, optou-se pelas imagens ventro-dorsal (VD) e laterolateral esquerda (LLE), confirmando o diagnóstico de trauma em sínfise mandibular mentoniana, conforme Foto 7. Optou-se inicialmente pela estabilização da paciente com fluidoterapia intravenosa, antibioticoterapia, anti-inflamatório e analgésicos com posterior limpeza das lesões e em seguida preparo do animal para procedimento cirúrgico de osteossíntese de sínfise mandibular com uso de fio e cerclagem $0,8 \mathrm{~mm}$. No dia três de março de dois mil e vinte a paciente retornou à clínica apresentando necrose em região mentoniana, exposição de implante cirúrgico e ósseo. A profissional explicou à tutora sobre a possibilidade de um tratamento realizado por uma aluna do UNICERP, com material biológico estéril de pele de tilápia do Nilo associando com o fio de cerclagem. Sendo autorizado pela mesma.

Tabela 1. Teste rápido de FIV/ FeLV em gata Sofia. Fonte: Clínica Veterinária Cães e Cia.

\begin{tabular}{lc}
\hline Exame & Resultado \\
\hline FeLV & Negativo \\
FIV & Negativo \\
Combo Felino & (25 de fevereiro de 2020 12:11) \\
\hline
\end{tabular}

A pele foi previamente preparada no Centro Universitário do Cerrado Patrocínio (UNICERP), em laboratório estéril. Para isso utilizou-se solução de clorexidina dergemante a $2 \%$ e higienizada com solução fisiológica $0,9 \%$. Repetiu-se a técnica por 3 vezes, sempre removendo todo material da couraça que não seria utilizado, preservando as escamas e o couro do produto. Após a higienização o material 
foi embalado, identificado e armazenado na geladeira para refrigeração, utilizando como meio de armazenamento $80 \%$ solução fisiológica e $20 \%$ de glicerina. Esse procedimento de higienização e refrigeração foi realizado durante 3 dias até atingir a proporção 100\% de glicerina. Após todo o processo a pele já é considerada pronta para o uso, devendo ser guardada, refrigerada e armazenada em embalagem a vácuo, contendo $100 \%$ de glicerina, como indicado na Foto 1.

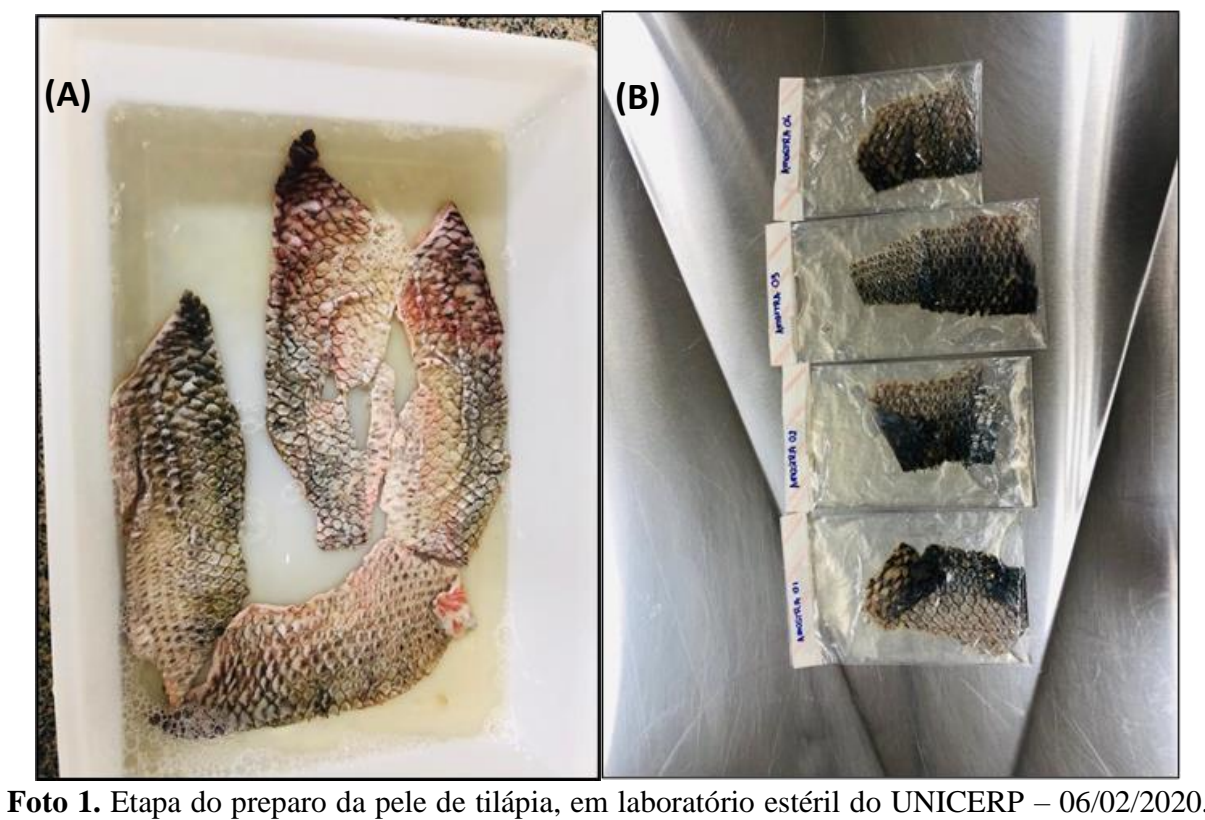

(A) higienização da pele e (B) pele previamente identificada e embalada.

Foi realizado, no dia vinte e oito de fevereiro de dois mil e vinte, a tricotomia nas bordas da lesão, antissepsia previa e antissepsia final, preparado todo o bloco cirúrgico para realização do procedimento. Com o animal sedado foi utilizado apenas porta agulha Mayo Hegar, fio nylon 3-0 pinça anatômica serrilhada, pinça anatômica, tesoura cirúrgica romba-romba e bandeja cirúrgica de aço inox. A paramentação da médica veterinária e dos auxiliares é essencial para que não haja contaminação na ferida e interferências no processo. A pele deve ser hidratada com solução fisiológica $0,9 \%$, durante 5 minutos antes do manuseio e remoção da tira a ser utilizada na lesão, como indicado na Foto 2.

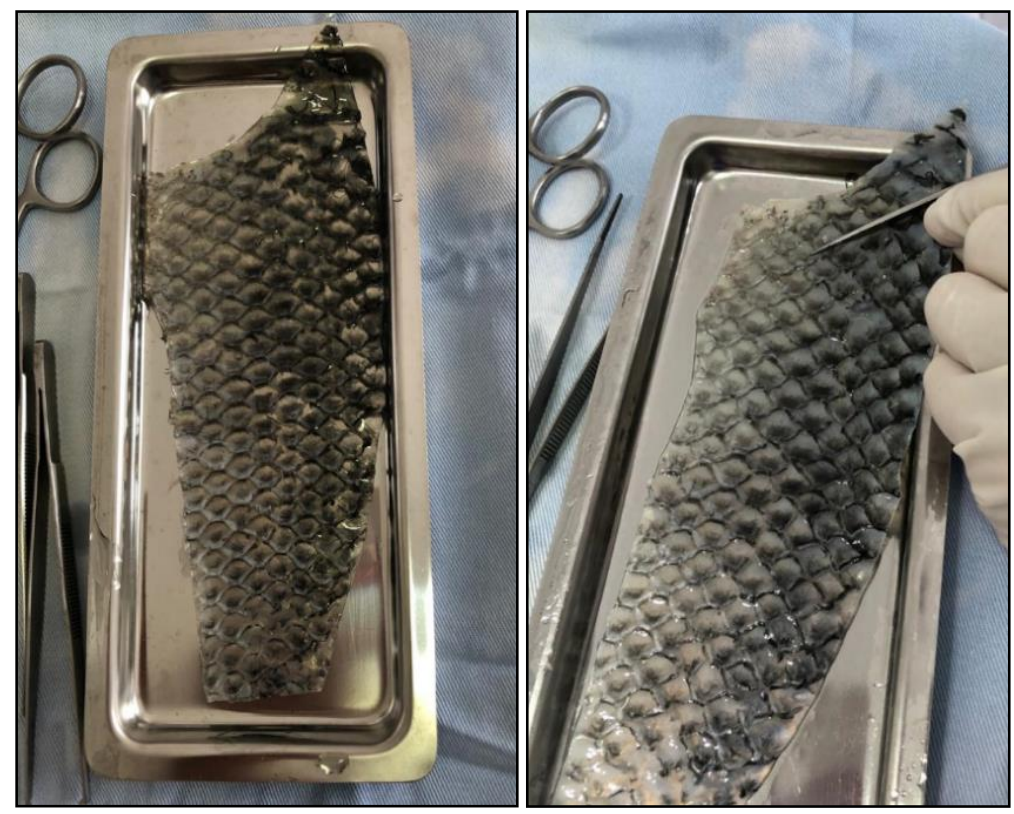

Foto 2. (A) Preparação da pele de tilápia sendo hidratada com solução fisiológica $0,9 \%$ (B) remoção da tira que será utilizada no paciente. 
Foi mensurado o tamanho das bordas com o uso de um paquímetro e, posteriormente, foi higienizado o local da lesão e debridação física com lâmina de bisturi número 24 para colocação do material biológico. As bordas apresentavam $2,1 \mathrm{~cm}$ de comprimento para $1,6 \mathrm{~cm}$ de altura, de acordo com as Foto $3 \mathrm{~A}$ e $\underline{3 \mathrm{~B}}$. As suturas foram feitas simples separado com medida de ancoragem na pele da musculatura do animal, utilizando fio nylon 3-0, conforme Foto 3C. Como tentativa para amenizar a fratura a médica veterinária optou por acoplar o fio de nylon entre os caninos, até que o animal restabelecesse formação de novas células ósseas. Para o tratamento em casa a profissional indicou a higienização com a limpeza do local com solução fisiológica $0,9 \%$ e o uso da pomada hidrogel Dersani ${ }^{\circledR}$ para lubrificação e estímulo da cicatrização.
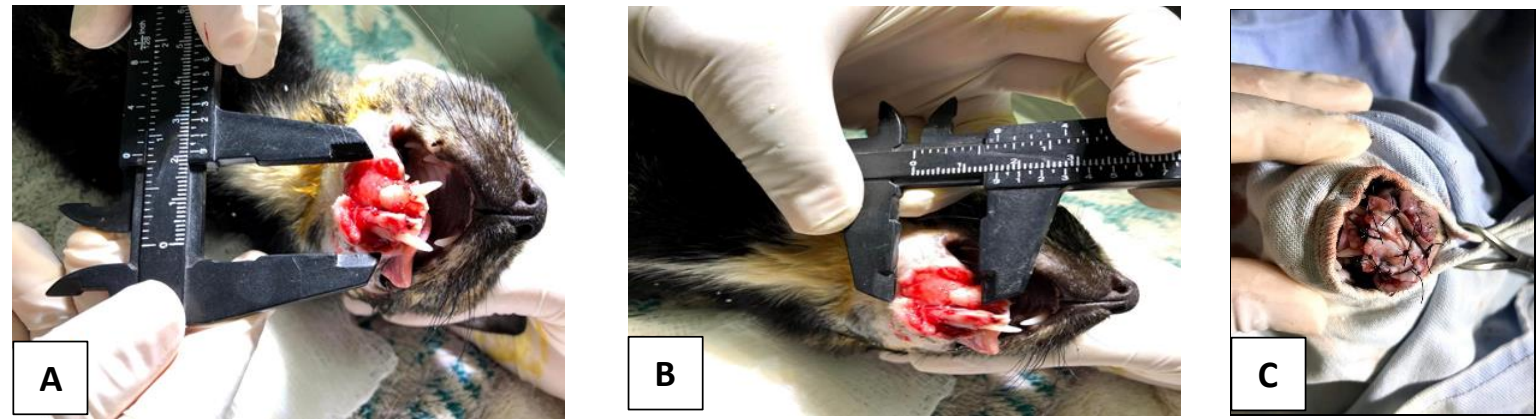

Foto 3. (A). Mensuração do comprimento com a utilização do paquímetro na ferida do paciente, apresentando $2,1 \mathrm{~cm}$ no início do tratamento. (B). Mensuração da altura da lesão da ferida do paciente com uso de paquímetro, apresentando $1,6 \mathrm{~cm}$. (C). Oclusão da ferida com o uso da pele de tilápia do Nilo, preconizou suturas simples separado com fio de nylon 3-0. O local foi hidratado com pomada hidrogel Dersani ${ }^{\circledR}$. Fonte: Clínica Veterinária Cães e Cia.

Após 4 dias o animal retornou para uma nova avaliação, apresentando absorção da pele de tilápia, recomendando-se um novo procedimento de oclusão com material biológico. O paciente foi novamente sedado, passando por todos os procedimentos pré-operatórios de assepsia e preparação do bloco cirúrgico com paramentação dos profissionais envolvidos. E só assim houve remoção das suturas que ancorava a pele na musculatura do paciente. Dessa vez a sutura realizada foi com nylon 4-0 utilizando novamente a sutura simples separado. Optou-se por um fio mais fino e delicado para que ancoragem da pele de tilápa na musculatura não formasse força tênsil, oferecendo mais conforto e bem-estar a gata. Foi realizado uma nova mensuração das medidas, constatando redução de $0,5 \mathrm{~cm}$ de comprimento e de altura continuou com as mesmas medidas, de acordo com Foto 4A, $\underline{4 \mathrm{~B}}$ e $\underline{4 \mathrm{C}}$.
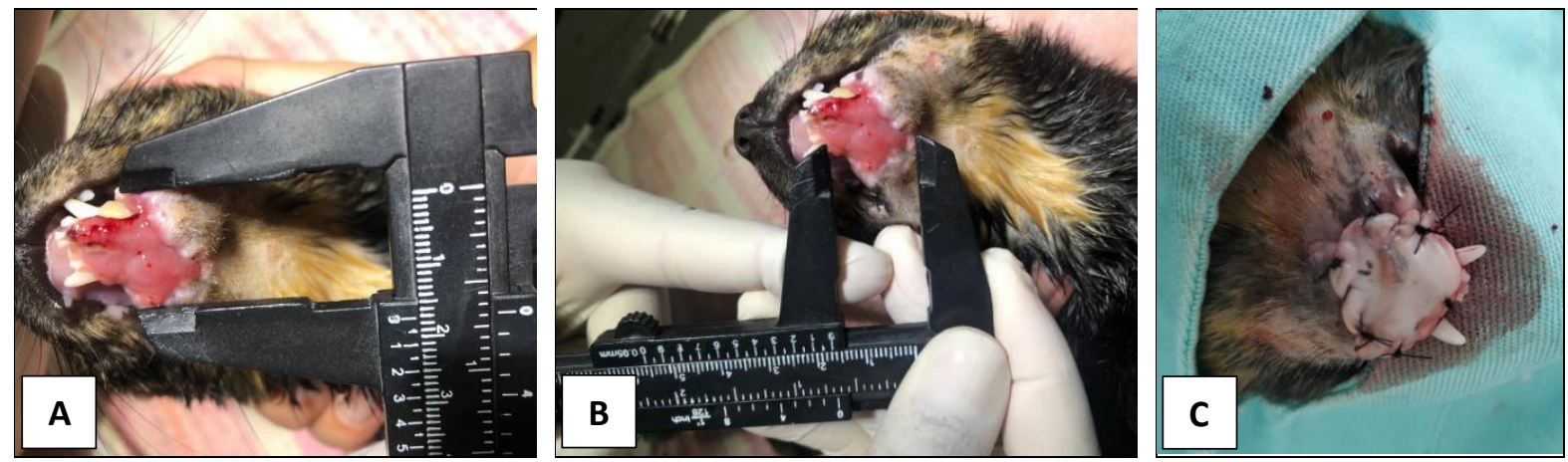

Foto 4. (A). Mensuração do comprimento da lesão com paquímetro, apresentando $1,5 \mathrm{~cm}$. (B). Mensuração da altura da lesão com uso do paquímetro, com 1,6 cm, não havendo alteração no tamanho da ferida. (C). Oclusão da ferida com a pele de tilápia do Nilo, utilizando fio nylon 4-0 e sutura simples separado, nota-se melhorar aderência ao trocar a espessura do fio aplicado na lesão. Fonte: Clínica Veterinária Cães e Cia.

A pele de tilápia foi trocada a cada 3-4 dias, sempre verificando a evolução da ferida e a presença de infecções e inflamações, esse processo ao todo foi realizado durante aproximadamente 17 dias. A última troca do curativo oclusivo usando a pele de tilápia do Nilo, realizada no $15^{\circ}$ dia o paciente já apresentava uma melhora significativa, conforme Foto $5 \mathrm{~A}$ e $\underline{5 \mathrm{~B}}$. Após a remoção do último curativo, verificado na Foto $5 \mathrm{C}$ a médica veterinária optou pela cicatrização por segunda intensão ainda utilizando a pomada Dersani ${ }^{\circledR}$ até o fechamento total da lesão apresentada pelo felino. 

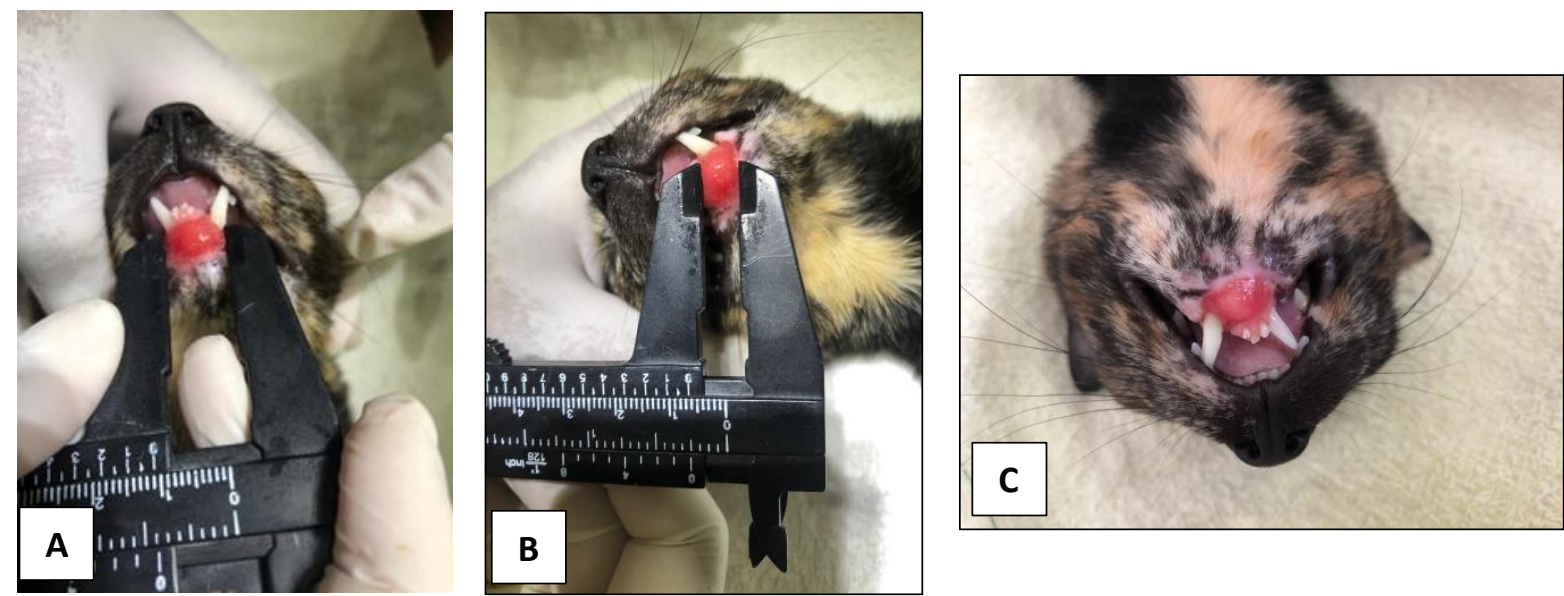

Foto 5. (A). Bordas apresentando $1,0 \mathrm{~cm}$ de lesão mensuradas pelo paquímetro, onde foi realizado a última troca de curativo oclusivo com material biológico de pele de tilápia. (B). Mensuração da altura da lesão utilizando paquímetro, apresentando $0,5 \mathrm{~cm}$ de bordas. (C). Remoção do último curativo oclusivo utilizando a pele de tilápia, no $17^{\circ}$ dia o animal apresentava a lesão quase cicatrizada, com fechamento gengival e sem fratura em sínfise mentoniana. Fonte: Clínica Veterinária Cães e Cia.

Atualmente a gatinha Sofia está totalmente recuperada, houve crescimento de epitélio e pelos ao redor de toda lesão. Conforme a musculatura ia crescendo na ferida junto com o epitélio que se formava, houve também preenchimento gengival, preenchendo o espaço fraturado entre os dentes incisivos. Com o preenchimento da gengiva, também facilitou para neoformação óssea, hoje a gata se alimenta normalmente de alimentos sólidos e pastosos, contatada nas Foto $6 \mathrm{~A}$ e $\underline{6 \mathrm{~B}}$.
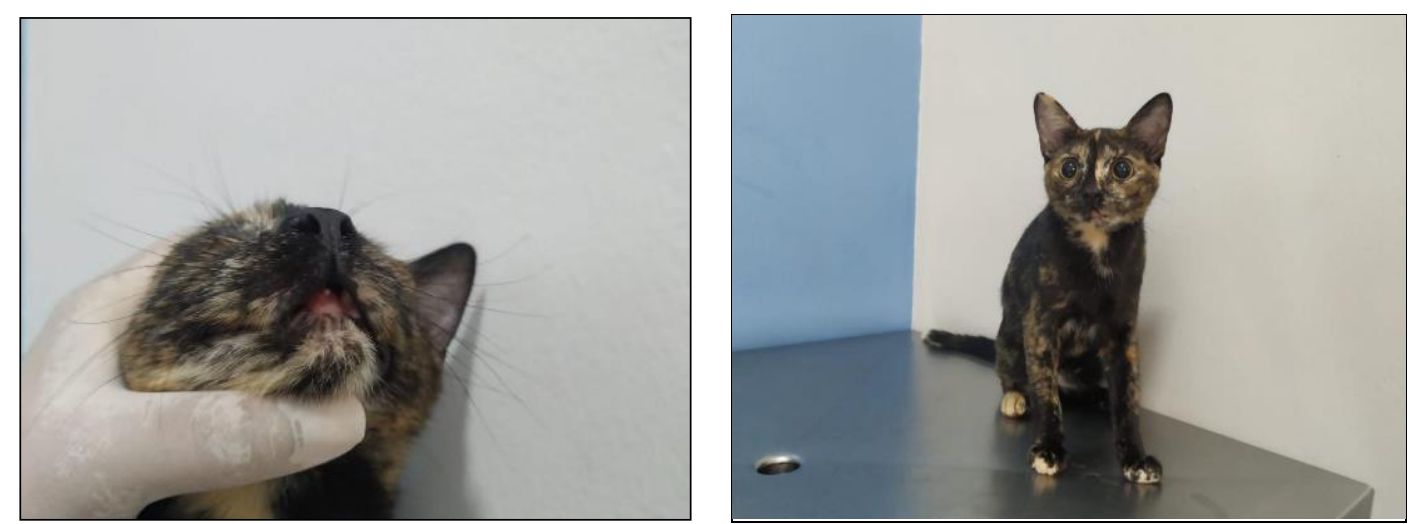

Foto 6. (A). Sofia já de alta após 23 dias de tratamento.

(B). Resultado da paciente após 23 dias de tratamento.

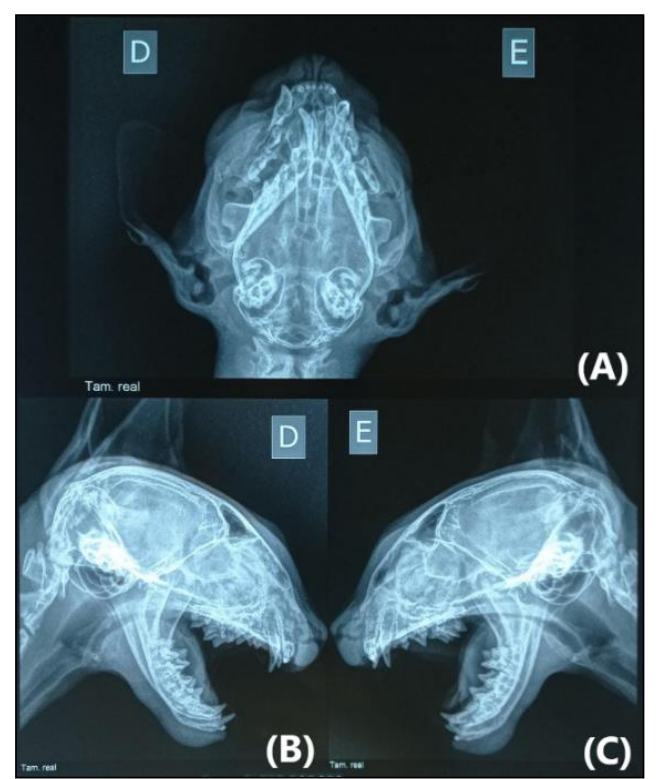

Foto 7. Raio-x realido na paciente Sofia no dia 25/02/2020, na imagem (A) posição ventro-dorsal (VD) demonstrando a fratura na sínfise mentoniana; imagem (B) latero-lateral direita (LLD); imagem (C) latero-lateral esquerda (LLE). Fonte: Clínica Veterinária Cães e Cia, 2020. 


\section{Discussão}

Enxertos heterólogos de origem animal como pele de porco, pele de rã, pericárdio bovino, submucosa de intestino de porco, são utilizados como curativos oclusivos biológicos chamados heteroenxertos no tratamento de feridas e traumas. Como inovação no uso de curativos oclusivos temporário, a pele de tilápia do Nilo tem mostrado ser um material nobre de alta qualidade e força tênsil de resistência excelente para promover proteção e hidratação do local. Durante o período de julho de 2015 a janeiro de 2016 na Universidade Federal do Ceará (UFC), Fortaleça, CE, Brasil, realizou um estudo no laboratório do Núcleo de Pesquisa e Desenvolvimento de Medicamento (NPDM), avaliando o uso da pele em tratamento de queimaduras de segundo grau superficial e profunda em ratos. Mostrando ser efetiva em todos os casos (Borella et al., 2019).

Ao realizarem estudos histológicos no material, contataram uma formidável quantidade de colágeno tipo I, ótima resistência à tração e boa umidade, similar a pele humana, tornando superior a outros biomaterias como pele de porco, rã e cães. No comparativo do experimento, conclui-se que a pele de tilápia do Nilo possui boa aderência à ferida, além de melhorar o processo de cicatrização. Durante o processo de esterilização, não foi encontrado presença de microrganismos patogênicos onde não houve alteração histológica do enxerto. Estudos recentes identificaram um novo tipo de colágeno (tipo I) com maior resistência térmica, sendo superior a outros bomateriais, o mesmo ainda auxilia nos fatores de crescimento de fibroblasto (FGF), onde promove a liberação do fator de crescimento de queratinócitos (KGF) e citocinas responsáveis pela oclusão da lesão (Borella et al., 2019).

A pele de tilápia mostra-se superior ao reduzir exsudatos e crostas formadas e ainda proporcionar obstrução da ferida por completo. Outros componentes presentes na pele de tilápia são peptídeos (hepcidinas, defensivas e interleucinas) que auxiliam no processo de cicatrização. No tratamento convencional de feridas, há necessidade de trocas diárias o que acarreta desconforto e algia ao paciente. Na utilização da pele de tilápia do Nilo, a mesma, poderá ficar na pele do paciente até o processo final de cicatrização ou até sua absorção pelo organismo do animal, reduzindo os desconfortos e algias geradas ao paciente ao manuseio. Esse fato deve-se pela pele aderir à ferida bloquear contato com o ambiente externo, reduzindo perdas de líquido e proteínas e evitando contaminações (Borella et al., 2019).

\section{Conclusão}

Pelo relato de caso, foi possível observar que a pele de tilápia do Nilo (Oreochromis niloticus), não apenas é utilizada como curativo por material biológico em queimaduras, mas também pode ser utilizado em traumas. Foi notória a evolução da ferida e queimadura na paciente Sofia, que apresentou melhora em 17 dias, tendo a conclusão do caso em 23 dias, observando-se a qualidade e bem-estar da paciente. A técnica demonstrou ser efetiva, trazendo agilidade no pós-operatório e monetariamente mais viável ao proprietário.

\section{Referências}

Borella, M. H. C., Carniatto, C. H. O., Silva, S. C. C., \& Huppes, R. R. (2019). Curativo oclusivo em feridas cirúrgicas: Comparação mascrocópica cicatricial entre colágeno de pele de tilápia e laserterapia. Encontro Internacional de Produção Científica, 1-4.

Dias, L. G. G. G., Dias, F. G. G., Cintra, C. A., dos Santos Honsho, C., \& de Mattos Júnior, E. (2012). Disjunção de sínfise mandibular em felino: Relato de caso. Enciclopeia Biosfera, 8(15), 708-720.

Lima-Júnior, E. M. L. (2017). Tecnologias inovadoras: uso da pele da tilápia do Nilo no tratamento de queimaduras e feridas. Revista Brasileira de Queimaduras, 16(1), 1-2.

Lima-Júnior, E. M., Moraes-Filho, M. O., Rocha, M. B. S., Silva-Júnior, F. R., Philopimin, C. M., \& Araújo, M. A. (2019). Elaboração, desenvolvimento e instalação do primeiro banco de pele animal no Brasil para o tratamento de queimaduras e feridas. Revista Brasileira de Cirurgia Plástica, 34, 349-354.

Lima-Junior, E. M., Picollo, N. S., Miranda, M. J. B. de, Ribeiro, W. L. C., Alves, A. P. N. N., Ferreira, G. E., Parente, E. A., \& Moraes Filho, M. O. de. (2017). Uso da pele de tilápia (Oreochromis niloticus), como curativo biológico oclusivo, no tratamento de queimaduras. Revista Brasileira de 
Queimaduras, 16, 10-17.

Lima Júnior, E. M. (2017). Avaliação pré-clínica da pele da tilápia (Oreochromis niloticus), como curativo biológico oclusivo, no tratamento de queimaduras. Universidade Federal do Ceará.

Miranda, M. J. B. (2018). Viabilidade da pele de Tilápia do Nilo (Oreochromis niloticus) como curativo biológico no tratamento de queimaduras. Anais Da Faculdade de Medicina de Olinda, 1(1), 49-52.

Nelson, R. W., \& Couto, C. G. (2015). Medicina interna de pequenos animais (Issue 1). Elsevier Editora.

Sousa, R. D. S. (2018). Estudo de substâncias químicas em óleos de coco, copaíba, calêndula e girassol utilizados no tratamento de feridas: uma abordagem teórica. Universidade Federal do Maranhão.

Torrisi, A. C., Silva, P. G. P., Carvalho, S. M. F. F., \& Miranda, M. J. B. (2018). Pele da tilápia do Nilo (Oreochromis niloticus) como curativo biológico no tratamento de queimaduras. Anais da Faculdade de Medicina de Olinda, 1(2), 65-68.

\section{Histórico do artigo:}

Recebido: 3 de dezembro de 2020 .

Aprovado: 15 de janeiro de 2021 .

Disponível online: 22 de abril de 2021.

Licenciamento: Este artigoé publicado na modalidade Acesso Aberto sob a licença Creative Commons Atribuição 4.0 (CC-BY 4.0), a qual permite uso irrestrito, distribuição, reprodução em qualquer meio, desde que $\mathrm{o}$ autore a fonte sejam devidamente creditados.

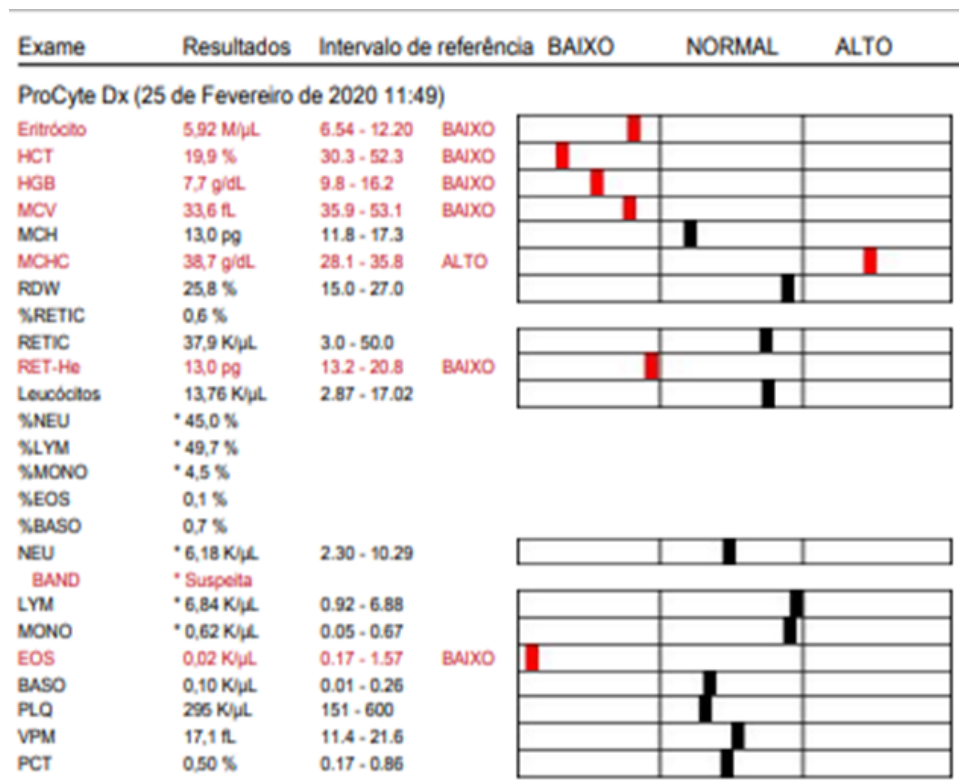

- Confrrme com dot piot e / ou revisalo de estrogaco de sangue.

Seq eritrócito

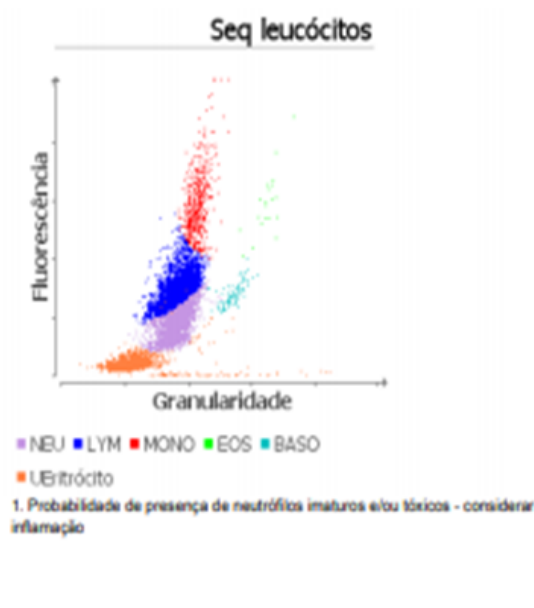

Impresso: 25 de Fevereiro de 2020 11:49

Página 1 de 1

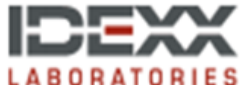

Anexo1. Hemograma completo da paciente Sofia. Fonte: Clínica Cães e cia. 